\title{
BANCROFTIAN FILARIASIS IN TRIBAL POPULATION OF BANKURA DISTRICT, WEST BENGAL, INDIA
}

\author{
Swapan Kumar Rudra And Goutam CHANDRA \\ Received September 3, 1997/Accepted June 1, 1998
}

\begin{abstract}
The state of West Bengal, India is endemic for bancroftian filariasis. But no information is available on filarial epidemiology among the tribal population of this state. Filariasis survey was conducted during night covering 1,386 tribal people of Banpura district, West Bengal. Indoor-resting mosquitoes were collected from human habitations of the tribal areas and dissected. Microfilaria rate, mean microfilarial density, disease rate and endemicity rate were $3.3 \%, 6.3 \%, 5.6 \%$ and $8.6 \%$ respectively. Per man-hour density, infection and infectivity rates of the vector Culex quinquefasciatus were found to be $9.0 \%, 2.7 \%$ and $0 \%$ respectively.
\end{abstract}

Key words: Bancroftian filariasis, microfilaria, tribal population, Culex quinquefasciatus

\section{INTRODUCTION}

Lymphatic filariasis is a major health problem of particular importance to India. According to WHO (1994), a total of 45.5 million persons are suffering from lymphatic filariasis in Indian subcontinent. Studies on filariasis in West Bengal were mainly restricted to the non-tribal population of Calcutta and its suburbs (Rao and Sukhatme, 1941; Rozeboom et al., 1968; Bhattacharya and Gubler, 1973; Hati et al., 1989; Chandra et al., 1994) except few in other areas (Iyenger, 1941; De and Chandra, 1994; Chandra and Hati, 1996). No work was conducted so far having information about the filarial situation in tribal population of this state. The present study has been formulated to gather first hand information on filariasis among the tribals and the vector status in tribal populated areas of Bankura district, West Bengal, India.

\section{Materials ANd Methods}

A survey was conducted covering $15 \%$ of the total population of 8 tribal villages namely Sukhosol, Dakhinasol, Baishnabbandh, Burroangari, Deldanga, Siberbandh, Nimdanga and Nabinnagar within a radius of 10 $\mathrm{km}$ around Sonamukhi Municipal town of Bankura district of West Bengal, India. A total of 1,386 tribal individuals of Santals, Kora and Munda classes were examined during the survey. These tribal classes are included in the racial group of kolid usually found in the North Deccan forests. They have strong totemistic beliefs. Matriarchal influence is observed. Skin colour is black brown (Das, 1988). Prior permission was taken by holding discussions with respective village heads and family members about the purpose of the study before survey. The survey was carried out between 19:00 hr to 22:00 hr. A blood sample of $20 \mu l$ was collected from all the family members by finger prick (Gubler et al., 1973) and thick blood smear was prepared. Then the slides were examined for the detection of microfilariae (Mf). Signs and symptoms of bancroftian filariasis from both sexes were recorded through physical examination. Age, sex and clinical history of each subject were also noted. Symptoms like filarial adenolymphangitis and epididymo-orchitis are accompanied by filarial fever and both of them often recur several times a year. Incidence of recurrence was recorded during taking the clinical history. Permanent oedema, which does not subside, without any apparent change of the skin is classified as lymphoedema. When the skin becomes chronically thickened along with hypertrophy of the sub-cutaneous tissues it is classified as elephantiasis.

For mosquito collection 16 spots were selected in 8 tribal villages ( 2 spots in each village). 10 human 
habitations were chosen from each spot and indoor resting mosquitoes were captured between 06:00 hr to 08:00 hr for $12 \mathrm{~min}$ from each habitation once a week from August 1994 to July 1995. Thus a total of 8 manhours were employed in each month for mosquito collection following the method of Holstein (1954) and WHO (1962). In the first week mosquitoes were collected from the habitations of spot no. 1, in the second week from the spot no. 2 and so on. Thus collections were made serially from spot no. 1 to 16 in one season (one season includes 4 months i. e. $16 \mathrm{wks}$ ). Collections were made in all the seasons of the year namely rainy (JulOct), winter (Nov-Feb) and summer (Mar-Jun) following the method of De and Chandra (1994). A total of 160 fixed human habitations were searched for mosquitoes in each season. Mosquitoes were dissected and examined to determine the prevalence $W$. bancrofti larvae. Statistical analysis were computed with the help of Normal deviate ' $Z$ ' (to compare rates) and Student's ' $\mathrm{t}$ ' test (to compare averages).

\section{RESUlTS AND Discussion}

\section{Parasitological and clinical studies}

The survey revealed an overall Mf rate, Mf density (Average load of Mf per positive person per $20 \mu l$ blood), disease rate and endemicity rate (rate of $\mathrm{Mf}$ carriers plus clinical cases; Mf positive clinical cases have been considered once) of $3.3 \%, 6.3 \%, 5.6 \%$ and $8.6 \%$ respectively in the present study area. Out of 8 villages surveyed only 4 were found to be with Mf positive patients, but diseased persons were recorded in all the villages. Variation in endemicity rate of filariasis was noted according to villages and endemicity rate was higher in those villages which were close to the urban areas.
Mf rate among the tribal population of the present study area $(3.3 \%)$ was almost same to that of the tribes of Panna district (3.8\%), Madhya Pradesh (Chand et al., 1996) and much lower than that of the tribes of Nancowry group of islands (11.9\%) in Andaman and Nicobar islands (Tewari et al., 1995). Information on filarial endericity among the tribes of India is very limited.

Age and sexwise details are shown in Table 1. Both Mf rate and Mf density among males (4.4\%; 7.7) were higher $(\mathrm{p}<0.05)$ than those in females $(2.2 \% ; 3.6)$ of the present study area as also found in Panna district. Though overall Mf rate was not very high in tribal villages of Bankura district, it was higher in the working age groups specially between 31 and 40 years in both male $(8.4 \%)$ and female $(5.8 \%)$. The time of blood collection between 19:00 and 22:00 hr was slightly early for nocturnally periodic strains which might cause slight underestimation in Mf rate. This is worthy mentioning that there are no electricity facility in the isolated tribal villages and so the tribal people go to bed within 8 p.m. usually. Male children below 10 years did not show Mf positivity. Mf density was noted to be the highest in the age group of $11-20$ years both in males $(10.1 \%$ ) and females $(7.0 \%)$ indicating that the people of tribal community of the study area became infected with filarial worms in their earlier age. Moreover, the existence of two female Mf positives at age $\leqq 10$ is a direct finding to support the idea of early age infection among tribals.

Different clinical signs and their age and sexwise distribution are presented in Table 2. Overall disease rate $(5.6 \%)$ was higher $(\mathrm{p}<0.05)$ than the Mf rate (3.3\%). Out of 78 clinical patients $5(6.4 \%)$ were $\mathrm{Mf}$ positive. Disease rate among males $(8.0 \%)$ was also higher $(\mathrm{p}<0.05)$ than that in females $(3.2 \%)$. Disease

Table 1 Microfilaria rate, Mf density and disease rate according to sex and age group among tribal villagers

\begin{tabular}{|c|c|c|c|c|c|c|c|c|c|c|c|c|}
\hline \multirow{2}{*}{$\begin{array}{c}\text { Age } \\
\text { group } \\
\text { (Years) }\end{array}$} & \multicolumn{4}{|c|}{ Male } & \multicolumn{4}{|c|}{ Female } & \multicolumn{4}{|c|}{ Total } \\
\hline & $\begin{array}{l}\text { No. } \\
\text { exa- } \\
\text { mined }\end{array}$ & $\begin{array}{l}\text { Mf } \\
\text { rate } \\
(\%)\end{array}$ & $\begin{array}{l}\text { Mf } \\
\text { density }\end{array}$ & $\begin{array}{l}\text { Disease } \\
\text { rate } \\
(\%) \\
\end{array}$ & $\begin{array}{l}\text { No. } \\
\text { exa- } \\
\text { mined } \\
\end{array}$ & $\begin{array}{l}\text { Mf } \\
\text { rate } \\
(\%)\end{array}$ & $\begin{array}{l}\text { Mf } \\
\text { density }\end{array}$ & $\begin{array}{l}\text { Disease } \\
\text { rate } \\
(\%) \\
\end{array}$ & $\begin{array}{l}\text { No. } \\
\text { exa- } \\
\text { mined } \\
\end{array}$ & $\begin{array}{l}\text { Mf } \\
\text { rate } \\
(\%) \\
\end{array}$ & $\begin{array}{l}\text { Mf } \\
\text { density }\end{array}$ & $\begin{array}{l}\text { Disease } \\
\text { rate } \\
(\%)\end{array}$ \\
\hline$\leqq 10$ & 142 & 0 & 0 & 0 & 134 & 1.5 & 6.5 & 0 & 276 & 0.7 & 3.2 & 0 \\
\hline $11-20$ & 215 & 6.5 & 10.1 & 8.4 & 194 & 1.0 & 7.0 & 1.0 & 409 & 3.9 & 8.5 & 4.9 \\
\hline $21-30$ & 154 & 3.9 & 6.3 & 9.1 & 133 & 1.5 & 4.5 & 7.5 & 287 & 2.8 & 5.4 & 8.4 \\
\hline $31-40$ & 95 & 8.4 & 5.2 & 15.8 & 104 & 5.8 & 1.5 & 3.8 & 199 & 7.0 & 3.3 & 9.5 \\
\hline $41-50$ & 55 & 3.6 & 6.0 & 14.5 & 68 & 2.9 & 3.5 & 5.9 & 123 & 3.3 & 4.7 & 9.8 \\
\hline $51-60$ & 31 & 3.2 & 5.0 & 3.2 & 46 & 2.2 & 3.0 & 4.3 & 77 & 2.6 & 4.0 & 3.9 \\
\hline $61-70$ & 10 & 0 & 0 & 0 & 5 & 0 & 0 & 0 & 15 & 0 & 0 & 0 \\
\hline $\begin{array}{c}\text { Total/ } \\
\text { Avg }\end{array}$ & 702 & $4.4^{*}$ & $7.7^{*}$ & $8.0^{*}$ & 684 & $2.2^{*}$ & $3.6^{*}$ & $3.2^{*}$ & 1,386 & $3.3^{*}$ & $6.3^{*}$ & $5.6^{*}$ \\
\hline
\end{tabular}


Table 2 Different filarial symptoms i. e adenolymphangitis, lymphoedema, elephantiasis, epididymo-orchitis and hydrocele according to sex and age group among tribal villagers

\begin{tabular}{|c|c|c|c|c|c|c|c|c|c|c|c|c|c|c|c|c|c|c|c|c|c|c|}
\hline \multirow{3}{*}{$\begin{array}{c}\text { Age group } \\
\text { (Years) }\end{array}$} & \multicolumn{4}{|c|}{ Adenolymphangitis } & \multicolumn{4}{|c|}{ Lymphoedema } & \multicolumn{4}{|c|}{ Elephantiasis } & \multicolumn{4}{|c|}{ Epididymo-orchitis Hydocele } & \multicolumn{6}{|c|}{ Total clinical symptom(s) of any sort } \\
\hline & \multicolumn{2}{|c|}{ Male } & \multicolumn{2}{|c|}{ Female } & \multicolumn{2}{|c|}{ Male } & \multicolumn{2}{|c|}{ Female } & \multicolumn{2}{|c|}{ Male } & \multicolumn{2}{|c|}{ Female } & \multicolumn{2}{|c|}{$\overline{\text { Male }}$} & \multicolumn{2}{|c|}{$\overline{\text { Male }}$} & \multicolumn{2}{|c|}{ Male } & \multicolumn{2}{|c|}{ Female } & \multicolumn{2}{|c|}{ Total } \\
\hline & No & $\%$ & No & $\%$ & No & $\%$ & No & $\%$ & No & $\%$ & No & $\%$ & No & $\%$ & No & $\%$ & No & $\%$ & No & $\%$ & No & $\%$ \\
\hline$\leqq 10$ & 0 & 0 & 0 & 0 & 0 & 0 & 0 & 0 & 0 & 0 & 0 & 0 & 0 & 0 & 0 & 0 & 0 & 0 & 0 & 0 & 0 & 0 \\
\hline & 0 & 0 & 0 & 0 & 2 & 0.9 & 2 & 1 & 0 & 0 & 0 & 0 & 7 & 3.3 & 9 & 4.2 & 18 & 8.4 & 2 & 1 & 20 & 4.9 \\
\hline $21-30$ & 7 & 4.5 & 7 & 5.3 & 0 & 0 & 3 & 2.3 & 0 & 0 & 0 & 0 & 3 & 1.9 & 4 & 2.6 & 14 & 9.1 & 10 & 7.5 & 24 & 8.4 \\
\hline & 3 & 3.2 & 4 & 3.8 & 0 & 0 & 0 & 0 & 0 & 0 & 0 & 0 & 3 & 3.2 & 9 & 9.5 & 15 & 15.8 & 4 & 3.8 & 19 & 9.5 \\
\hline $41-50$ & 2 & 3.6 & 3 & 4.4 & 0 & 0 & 0 & 0 & 0 & 0 & 1 & 1.5 & 0 & 0 & 6 & 10.9 & 8 & 14.5 & 4 & 5.9 & 12 & 9.8 \\
\hline $51-60$ & 0 & 0 & 2 & 4.3 & 0 & 0 & 0 & 0 & 0 & 0 & 0 & 0 & 0 & 0 & 1 & 3.2 & 1 & 3.2 & 2 & 4.3 & 3 & 3.9 \\
\hline $61-70$ & 0 & 0 & 0 & 0 & 0 & 0 & 0 & 0 & 0 & 0 & 0 & 0 & 0 & 0 & 0 & 0 & 0 & 0 & 0 & 0 & 0 & 0 \\
\hline Total/Avg* & 12 & $1.7^{*}$ & 16 & $2.3^{*}$ & 2 & $0.3^{*}$ & 5 & $0.7^{*}$ & 0 & 0 & 1 & $0.1^{*}$ & 13 & $1.9^{*}$ & 29 & $4.1^{*}$ & 56 & 8.0 & 22 & 3.2 & 78 & 5.6 \\
\hline
\end{tabular}

rate was higher in the working age groups (21-50 years) both in males and females. Elephantiasis in the leg was noticed in a 47 year old woman only.

\section{Mosquito study}

A total of 2,216 female mosquitoes of 7 species were collected which included Culex quinquefasciatus (39.1\%), Cx. vishnui group (13.9\%), Anopheles subpictus (10.0\%), An. vagus (27.6\%), An. barbirostris (7.6\%), Armigeres subalbatus (1.2\%) and Mansonia indiana (0.6\%). Cx. quinquefasciatus was incriminated as the vector of $W$. bancrofti in these tribal villages. Average per man-hour density of $C x$. quinquefasciatus was 9.0 (ranging from 7.0 to 11.3 in different months). Availability of vector species in human habitations showed no seasonal $(\mathrm{p}>$ $0.05)$ variations as indicated by the prevalence in rainy season $(37.8 \%)$, winter $(34.9 \%)$ and summer $(27.2 \%)$. Out of total 23 infected $C x$. quinquefasciatus, 13 (56.5\%), $6(26.1 \%)$ and $4(17.4 \%)$ were found to carry Mf, 1 st stage and 2nd stage larvae of $W$. bancrofti respectively. No 3rd stage larva was detected in the wild vector population. Overall vector infection rate was $2.7 \%$ (ranging from $0 \%$ to $4.7 \%$ in different months). Seasonal vector infection rates were $3.0 \%, 2.3 \%$, and $2.5 \%$ in rainy season, winter and summer respectively without ( $>0.05)$ any marked variation. Vector infection rate and infectivity rate $(2.7 \%, 0 \%)$ in the present study area were lower than those of Panna district $(4.9 \% ; 1.0 \%)$.

\section{Life style of tribals and vector mosquito}

Less intensity of filarial infection among females is common in all the endemic places in India as they wear more cloths and are less exposed to mosquito bites. As the tribes are labour class poor people, all the family members except old age people work in the field. They are usually not provided with employment in their own villages. So they used to spend a long time of the year in non-tribal areas for employment with family and children. Low vector infectivity rate $(0 \%)$ indicates that transmission cycle of filarial worm is not very active in the tribal villages. Probably they carry the infection from some highly endemic places outside where they used to go for cultivation work, indicating a correlation of higher infection among working age groups. Tribal people generally live in moderate or dense forests usually isolated from urban areas. They maintain a separate socio-cultural heritage and are more close to nature. In stead of ill developed sanitary structures, associated with indiscriminate urbanization (commonly found in the non-tribal areas), the tribes keep their houses and surroundings in such a manner (neat and clean) as to be protective against vector breeding. Man-hour density of vector species in the tribal areas is much lower than those of the non-tribal areas studied so far in West Bengal. Informations gathered during the presest work will be of immense help to formulate an effective control strategy. Use of bed nets during the 3rd quadrant of night (12 midnight to 3 a. m.) as suggested by Chandra (1995) will be useful for protection against infection specially when they stay in non-tribal areas for work. Health education through community participation may be useful along with chemotherapy and vector control.

\section{REFERENCES}

1) Bhattacharya, N. C. and Gubler, D. J. (1973): A survey for bancroftian filariasis in the Calcutta area. Indian J. Med. Res., 61, 8-11

2 ) Chandra, G. (1995): Peak period of filarial transmission. Am. J. Trop. Med. Hyg., 53(4), 378-379

3 ) Chandra, G., Banerjee, A. and Hati, A.K. (1994): Current 
filariasis situation in some pockets of Calcutta. Bull. Cal. Sch. Trop. Med., 42, 4-7

4 ) Chandra, G. and Hati, A.K. (1996): Filariasis survey in a rural area of west Bengal. J. Commun. Dis., 28(3), 206208

5 ) Chand, G., Pandey, G.D. and Tiwary, R.S. (1996): Prevalence of $W$. bancrofti infection among the tribals of Panna district of Madhya Pradesh. J. Commun. Dis., 28(4), 304-307

6 ) Das, B.M. (eds.) (1988): Outlines of physical Anthropology. pp. 219. Kitab Mahal, Allahanad, India.

7 ) De, S.K. and Chandra, G. (1994): Studies on the filariasis vector Culex quinquefasciatus at Kanchrapara, West Bengal. Indian J. Med. Res., 99, 255-258

8 ) Gubler, D.J., Inui, T.S., Black, H.R. and Bhattacharya, N.C. (1973): Comparisons of microfilaria dinsity in blood samples by fingerprick, venipuncture and ingestion by mosquitoes. Am. J. Trop. Med. Hyg., 22, 174-178

9 ) Hati, A.K., Chandra, G., Bhattacharya, A., Biswas, D., Chatterjee, K.K. and Dwibedi, H.N. (1989): Annual transmission potential of bancroftian filariasis in as urban and a rural area of West Bengal, India. Am. J.
Trop. Med. Hyg., 40, 365-367

10) Holstein, M.H. (1954): Biology of Anopheles gambiae. WHO Monograph. Ser., 9, 1

11) Iyenger, M.O.T. (1941): Occurrence of $W$. bancrofti infection in a rural area. Indian J. Med. Res., 29, 677-679

12) Rao, S.S. and Sukhatme, P.V. (1941): Seasonal variation in the incidence of filarial lymphangitis. Indian J. Med. Res., 29, 209-223

13) Rozeboom, L.E., Bhattacharya, N.C. and Gilotra, S.K. (1968): Observations on the transmission of filariasis in urban Calcutta. Am. J. Epidem., 87, 616-632

14) Tewari, S.C., Hiriyan, J. and Reuben, R. (1995): Epidemiology of subperiodic $W$. bancrofti infection in the Nicobar islands, India. Trans. Roy. Soc. Trop. Med. Hyg., 89, 163-166

15) WHO (1962): Report of the Expert Committee on Filariasis. Tech. Rep. Ser. No. 233, World Health Organization, Geneva, p. 37

16) WHO (1994): Peport of a consultative meeting held at the University Sains Malaysia Penang, Malaysia: Lymphatic Filariasis Infection \& Disease: Control Strategies/TDR/ CTD/FIL/PENANG/94.1 